Infant and Child Development (2004), 13, 435-450

\title{
HEALTHY AND CHRONICALLY-ILL CHILDREN'S GENERALISATION OF ILLNESS TO BIOLOGICAL AND NON-BIOLOGICAL CATEGORIES
}

Eithne Buchanan-Barrow, Martyn Barrett and Mariangela Bati.

University of Surrey, Guildford Surrey, GU2 7XH

Correspondence to: Dr Eithne Buchanan-Barrow, Department of Psychology, University of Surrey, Guildford, GU2 7XH.

Tel: 01483686871

Fax: 01483689553

Email: eithne.buchanan-barrow@surrey.ac.uk

Short title: children's reasoning about biological categories 


\begin{abstract}
Using children's naïve theory of biology as a framework, this study investigated children's developing understanding of illness by examining their generalisation of illness to biological and non-biological categories. In addition to differences associated with age, the children's health status was investigated for any possible links with their understanding. Healthy and chronically-ill children, aged 4-11 years, were randomly assigned to one of three conditions, according to which exemplar (child, dog or duck) was described as suffering from an imaginary illness. Using a card-sorting technique, the children assessed whether each entity out of 30 entities (five representatives in each of six categories: humans, mammals, non-mammals, birds, plants and artifacts) could be afflicted by that illness. The children's generalisations indicated a grasp of the distinctiveness of the various categories, although they seemed less certain about the biological status of plants. Furthermore, the type of exemplar on which the children had been taught influenced their responses. However, the children's reasoning appeared unaffected by their health status and largely unaffected by age or gender.
\end{abstract}

Key words: children, illness, biology, naïve theory 


\section{Introduction}

The development of children's beliefs about health and illness has significant practical implications for educating chronically-ill children about their disease, medical treatment and hospital admission, as pediatric patients require the appropriate explanations to assist their coping with the stress of their illness (Eiser, 1990). Research into children's naive theory of biology has proved to be a productive perspective on children's biological thinking and offers a theoretical framework for researching children's understanding of illness. The 'theory' approach postulates that children acquire content-specific systems of knowledge rather than domain-independent ones, and three particular domains have been investigated, namely physics, psychology and biology (Wellman \& Gelman, 1992, 1998). According to Wellman (1990), a theory requires ontological distinctions, coherence and a causal-explanatory framework. Following Wellman's general framework, Hatano and Inagaki (1994) propose that there are three important components involved in biological thinking: 1) knowledge to ascertain the specific entities which fall within the biological domain; that is the distinction between the living and the non-living; 2) a mode of inference which permits integrated and reasonable predictions for attributes or behaviours of biological entities; and 3) a nonintentional causal explanatory framework for the behaviours relevant to biological processes.

Therefore, within a 'theory' approach, the child is portrayed as capable of forming and using complex mental structures that function as explanatory systems (Rosser, 1994), although the approximate age of development of such skills is unclear. With respect to biology, Carey (1995) believes that young children have a fairly limited ability to reason about biological systems. She postulates that children's biological understanding 
develops as a consequence of increased knowledge together with some structural change, as earlier psychologically-based theories evolve into biological ones. On the other hand, some studies have suggested that children acquire an understanding of an autonomous domain of biology at a much younger age, even though they may lack specific knowledge of biological systems (Keil, 1989; Inagaki \& Hatano, 1996).

Within this 'theory' perspective, some studies have indicated that children do display theoretical thinking about illness. For example, investigations of children's thinking about illness causality have found that pre-school children have well-developed theories about the ways certain kinds of illnesses are transmitted (Siegal, 1988; Siegelman et al., 1993; Inagaki, 1997). However, the most important finding in this area has been that young children generally hold contagion and contamination to be the most likely causes of physical problems, regardless of the nature of illness/injury involved (Kister \& Patterson, 1980; Hergenrather \& Rabinowitz, 1991; Kalish, 1999). As young children's most likely experience of illness is with such infectious illnesses as colds, measles and chicken-pox, it is perhaps unsurprising that their early model of illness should be based on contagion and contamination (Campbell, Scadding \& Roberts, 1979; Kalish, 1999).

Four possible theories of children's understanding of the transmission of infection have been reported in the literature: the associational model, the physical model, the simplebiological and the differentiated-biological (Kalish, 1999). With the associational model, children believe that contagion and contamination occur, without any evident contact, through proximity or magic (Bibace \& Walsh, 1980; Frazer, 1981). With the physical model, children regard actual physical contact as necessary for infection to take place, but the agents of infection are understood to be inert material entities. In particular, children attribute this action to germs as the invisible causal agents in illness 
(e.g. Solomon \& Cassimatis, 1999; Kalish, 1999). However, with the simple-biological model, the living nature of germs is fully recognised and thus these agents of infection are understood to be living organisms which act on other living entities. Finally, with the differentiated-biological model of infection, the distinctive types and attributes of a range of infectious agents are acknowledged. While there is little direct evidence that young children hold a biological concept of infection (Kalish, 1999), Kalish (1996) has argued that children's predictions of contagion do involve the idea of an intermediate mechanism and therefore are not based on simple associations. As children lack the more detailed and specialised knowledge necessary for a biological understanding of infection, their reported thinking approximates to a physical model. However, it is also possible that they hold a co-existence model and that they may not view infection in uniquely biological ways (Kalish, 1999). In other words, children may have multiple explanations for infectious processes, simultaneously holding both biological and nonbiological accounts, such as an associational model of infection.

Children who have experienced illnesses other than the common infectious diseases of childhood might be expected to display a different understanding of illness from that of normally healthy children, as a consequence of their additional exposure to poor health. However, investigations of the thinking of sick children about illness have produced inconclusive findings. While some early work suggested that the understanding of chronically-ill children remained unaffected by their experiences (Brewster, 1982), there has been more general agreement that sick children's thinking is affected, although the direction of that influence has been disputed. Some studies have proposed that sick children display a more sophisticated understanding of illness, possibly because their experiences facilitate their comprehension (Bibace \& Walsh, 1980; Feldman \& Varni, 1985; Rubovits \& Siegel, 1994). Other studies have proposed an 
interaction between age and experience; with age, chronically-ill children do display greater illness understanding, while younger children remain unaffected (Campbell, 1975; Redpath \& Rogers, 1984; Crisp et al., 1996). On the other hand, other studies have suggested that the normal development of thinking about health and illness is actually delayed in chronically ill children (Nagera, 1978: Eiser et al., 1988; Shagena et al., 1988; Perrin et al., 1991; Sayer et al., 1993), resulting in a less sophisticated understanding. Berry et al. (1993) highlighted the number of long-term child-sufferers with Juvenile Rheumatoid Arthritis holding misconceptions about their illness, despite their routine exposure to information and advice, giving rise to the possibility that some chronically-sick children are resistant to attempts to inform them about their illness.

However, while the genesis, direction, and extent of any influences on chronically-ill children's understanding may be unclear, it is nevertheless evident from these studies that individual differences in both sick and healthy children is an area which needs further investigation. Furthermore, there are two points of criticism of the previous research into healthy versus sick children's thinking about illness. First, studies have generally utilised a Piagetian cognitive-developmental perspective, rather than the 'theory' approach. However, the naïve theory perspective, with its emphasis on domainspecific knowledge as opposed to domain-general knowledge, may provide a better framework for an examination of individual differences. Secondly, most of the previous research has focused on the children's knowledge of the facts of illness rather than their conceptual reasoning about illness. However, an investigation of children's understanding of illness, using an hypothetical disease as opposed to 'real' illnesses, should reveal something of their naive theory of illness which may differentiate the thinking of healthy from that of sick children. 
Therefore, this present study of healthy and sick children's thinking about illness used children's naive theory of biology as the theoretical perspective, with a study by Keil (1989) providing the general framework. Keil investigated children's ontological knowledge of phenomena by exploring their understanding of ontological boundaries through transformations (e.g. about whether it is possible for a horse to be turned into a zebra or a cactus into a porcupine). He revealed that children do have an intuitive taxonomy for structuring the biological domain and that they resist impossible biological transformations while accepting others as more plausible. Therefore, this present study also explored children's ontological boundaries, but using the generalisation of illness to do so, by examining the extent to which children generalise a made-up illness, plinkitis, to other biological and non-biological entities. As plinkitis is not a real disease, the children would not have been able to draw upon any acquired knowledge about this particular disease in order to answer questions about it, but would have to use their naive or implicit theories of illness to make their predictions. To that end, the description of plinkitis was restricted to very basic terms so that children would not be prompted to associate it with any known illness.

Furthermore, this study examined Carey's belief that young children view humans as the prototypical biological entity (Carey, 1995). According to Carey (1995), children before the age of about 10 extend their thinking to other biological categories according to the similarity or proximity of other entities to humans. For example, when taught on a human exemplar, children not only tend to generalise more to other ontological categories, but the likelihood of such generalisations is greater the closer the links between the human exemplar and the other entities (Carey, 1995). Therefore, the study explored children's generalisation of illness from three different exemplars (child, dog or duck) in order to examine whether the use of non-human exemplars did result in a 
lower degree of generalisation than for the human exemplar and also to probe for any differences between the healthy and chronically-sick children. ${ }^{1}$

\section{Method}

\section{Participants}

Two hundred and ninety-one children were randomly recruited from school years Reception to Year 6 (age range: 4.9-11.9 years) in two primary schools in England. For the purposes of the analysis the children were grouped into three age-groups: (1) Young group with 119 children from three school years (Reception, 1, and 2): 59 girls (mean age $=6.4$ years, age range $=4.9-7.8$ years) and 60 boys (mean age $=6.2$ years, age range $=4.9-7.8$ years $)$. (2) Middle group with 85 children from two school years (3 and 4): 46 girls (mean age $=9.0$ years, age range $=7.9-9.9$ years) and 39 boys (mean age $=8.9$ years, age range $=8.1-9.9$ years). (3) Old group with 87 children from two school years ( 5 and 6$)$ : 45 girls (mean age $=10.8$ years, age range $=9.9-11.8$ years) and 42 boys (mean age $=10.9$ years, age range $=9.9-11.9$ years $)$.

In addition, 96 children (age-range: 4.5-11.8 years) diagnosed as having a chronic condition participated in the present study: 13 children with cystic fibrosis, 19 children with diabetes, 14 children with epilepsy, 42 children with asthma, and 8 children with other conditions such as leukemia, osteogenesis imperfecta, and retinoblastoma. The children were recruited from a children's hospital in England. The children were also grouped into three age-groups: (1) Young group with 44 children: 21 girls (mean age $=$

\footnotetext{
${ }^{1}$ Note that the present study examined children's taxonomically horizontal generalisations of illness across different biological and non-biological entities, in order to examine the extent to which children understand the ontological boundaries which exist between different categories. In its emphasis on children's understanding of horizontal taxonomic relationships and differences, it therefore differs from the work of Atran (1998), who instead examined people's understanding of vertical taxonomic biological relationships (e.g. between bird - vulture - black vulture - red-headed black vulture).
} 
6.5 years, age-range $=4.7-7.8$ years) and 23 boys (mean age $=6.3$ years, age-range $=$ 4.5-7.8 years); (2) Middle group with 31 children: 17 girls (mean age $=8.8$ years, agerange $=8.8-9.8$ years) and 14 boys (mean age $=9.1$ years age-range $=8.1-9.8$ years); (3) Old group with 20 children: 6 girls (mean age $=10.6$ years, age-range $=10.1-11.7$ years) and 14 boys (mean age $=10.4$ years, age-range $=10.1-11.8$ years). These children formed the chronically-ill (henceforward CI) group in the study.

All the children's verbal IQs were measured by the British Picture Vocabulary Scale (BPVS) (Dunn et al., 1982) in order to ensure that the healthy and chronically-ill children did not differ in their verbal IQ. A 2 (health status) x 3 (age) ANOVA revealed no significant differences between the BPVS scores obtained by the healthy and CI children (Healthy mean score $=102.02, \mathrm{sd}=14.7, \mathrm{CI}$ mean score $=99.53, \mathrm{sd}=18.5$ ), nor between the three age-groups (Young mean score $=100.93$, sd $=16.9$, Middle mean score $=101.24, \mathrm{sd}=15.3$, Old mean score $=100.81, \mathrm{sd}=20.3)$, and there was no significant interaction between health status and age. There were thus no biases evident on the BPVS in the samples.

In order to examine any differences between the thinking of children and that of adults, $961^{\text {st }}$ year university students were recruited and given exactly the same task to perform, but in a questionnaire format (mean age $=19.2$ years, $\mathrm{sd}=1.6)$.

\section{Materials}

Thirty cards, each measuring $5 \times 2.5$ ins., naming five entities from each of six ontological categories, were used in the sorting task. On each card, the name of one entity was written clearly. The ontological categories from which the entity names were drawn were (a) human beings (man, woman, boy, girl, baby), (b) mammals (elephant, 
cow, sheep, cat, mouse), (c) non-mammals (crocodile, tortoise, frog, butterfly, ant), (d) birds (turkey, swan, chicken, blackbird, robin), (e) plants (oak tree, apple tree, rose bush, daffodil, dandelion) and (f) hand-made artifacts (house, car, bicycle, computer, cup). The generalisation entities were chosen to represent a full range of sizes within each category. In addition, there were three boxes, measuring $9 \times 6.5 \times 7$ ins., each clearly labelled with one of the three possible answers given by the children: can get plinkitis, cannot get plinkitis, I don't know. Finally, three additional cards were used, each showing a simple black and white line drawing of one of the exemplars in reference to which the children were taught about the imaginary illness. The three exemplars used were a child, a dog and a duck, chosen from the midpoint size of the categories of human beings, mammals and birds respectively, in order to minimise any possible restrictions on the children's generalisations based on size of exemplar.

\section{Procedure}

Children were randomly assigned to either the child, dog or duck condition. Healthy children: Parents gave consent by letter to their children taking part. The children were tested individually for about fifteen minutes. The child was told that the interviewer was writing a book for children concerning the body and they were reassured that there were no right or wrong answers. Immediately after the completion of the task, the short form of the BPVS was administered to each of the participants. Chronically-ill children: The parents were told of the study by letter, prior to their child attending the clinic. Ninetysix children agreed to take part, with seven children declining. Exactly the same procedure was followed as with the healthy children, again with the children being interviewed individually. 
The three boxes with open tops without lids were put on the table. Each box represented one of the possible answers which could be given by the child: can get plinkitis, cannot get plinkitis, I don't know. The boxes were placed on the table in the above order for the first child so that the child could clearly see what was written on each box. For the second child the order cannot get plinkitis, can get plinkitis, I don't know was used. These two orders were alternated accordingly throughout the testing in order to control for possible left-right response biases. The interviewer then described an illness, plinkitis, in the following way.

'Plinkitis is an illness. Here is a picture of a child (dog or duck; depending on which exemplar the child was taught on). Children (dogs or ducks) can get plinkitis. When children (dogs or ducks) get plinkitis they feel dizzy and have to stay really, really still or they feel worse. They also have a high temperature and they feel very ill.

The interviewer then showed the cards naming the various entities, in a different randomised order for each child. The children were asked to put each card in the appropriate box, according to their belief that the particular entity could or could not get plinkitis, or that they did not know.

\section{Results}

The children's thinking about the ontological categories was analysed as follows: first, by ANOVAs on the children's basic scores (i.e. the total number of entities out of five chosen as susceptible to plinkitis within each of the six categories); secondly, by Configural Frequency Analysis (CFA) on children's responses for each category for each of the three exemplars used. In addition, log linear analyses investigated any 
possible links between children's significant response patterns (as generated by the CFAs) and their age, health status or gender.

\section{ANOVAs}

The total number of cards for each ontological category placed by the child into the can get plinkitis box was calculated; in each case, the scores could range from 0-5. The mean scores obtained by the children were first analysed by using three 5-way 3 (age) $\mathrm{x}$ 2 (healthy vs CI) x 2 (gender) x 3 (exemplar) x 6 (type of ontological category) mixed ANOVAs with independent groups on the first four factors and repeated measures on the fifth factor (the number of can get plinkitis responses). This revealed main effects of category as well as category by exemplar and category by group interaction effects.

Because of the category by exemplar interaction effects and the complexity of the findings, the data were also analysed for each exemplar separately using three separate 3 (age) $\times 2$ (gender) x 2 (healthy vs CI) x 6 (type of category) mixed ANOVAs, with independent groups on the first 3 factors and repeated measures on the fourth factor. There were main effects of type of category with all exemplars, indicating that children do perceive differences between the various categories of entities when exemplars belong to different ontological categories. However, as there were no significant effects involving the children's health status, Tables 1-3 do not separate out the healthy vs chronically-ill children's scores. All the significant effects found in the three ANOVAs are shown at the foot of each table. The main effects of category were explored further using Bonferroni-corrected post hoc t-tests and the results shown in Table 4.

For comparison purposes, the mean scores of the adult participants are also shown in Tables 1-3. With respect to the child exemplar, the adults were significantly more likely 
than the Old group of children to generalise to mammals ( $t(66)=-2.23, \mathrm{p}<.05)$, to nonmammals $(\mathrm{t}(66)=-2.53 . \mathrm{p}<.05)$ and to birds $(\mathrm{t}(66)=-2.03, \mathrm{p}<.05)$. With respect to the dog exemplar, the adults were significantly more likely than the Old group of children to generalise to mammals $(\mathrm{t}(69)=-2.00, \mathrm{p}<.05)$, to non-mammals $(\mathrm{t}(69)=-2.44$, $\mathrm{p}<.05)$ and to birds $(\mathrm{t}(69)=-2.46, \mathrm{p}<.05)$. With respect to the duck exemplar, the adults were significantly more likely than the Old group of children to generalise to humans $(\mathrm{t}$ $(63)=-2.75, p<.05)$. All other differences between the adults and the Old group were non-significant.

\section{* * INSERT TABLES 1-4 ABOUT HERE * *}

\section{Differences Associated with Category}

Children taught on the child exemplar claimed that humans were significantly more likely than all the other categories to get plinkitis (see Tables 1 and 4). After human beings, mammals were the most likely to get plinkitis, followed by birds, non-mammals and plants. The category of hand-made artifacts was seen by children in all age-groups as the least likely to get plinkitis. However, the differences between plants and handmade artifacts were not significant.

Children taught on the dog exemplar claimed that mammals were significantly more likely than all the other categories to get plinkitis (see Tables 2 and 4). After mammals, birds were the most likely to get plinkitis, followed by non-mammals/humans and then by plants/hand-made artifacts. Again the category of hand-made artifacts was seen by children in all age-groups as the least likely to get plinkitis. However, the differences between humans and non-mammals, and between plants and hand-made artifacts, were not significant. 
Children taught on the duck exemplar claimed that birds were significantly more likely than all the other categories to get plinkitis (see Tables 3 and 4). After birds, mammals were the most likely to get plinkitis, followed by non-mammals, and humans, and then by plants. The category of hand-made artifacts was seen by children in all age-groups as significantly the least likely to get plinkitis. However, the differences between humans and non-mammals were not significant.

\section{Differences Associated with Age}

There were no main or interaction effects involving age on the can get plinkitis responses with the child as exemplar. However, with children taught on the dog exemplar, an interaction effect between category and age was revealed on the can get plinkitis responses. Post hoc Scheffe tests $(\mathrm{p}<0.05)$ revealed that the Young group of children was less likely to generalise to human beings than the Old group. In addition, the Middle group of children was significantly more likely to generalise to birds than the Old group.

Children taught on the duck exemplar also revealed an interaction effect between category and age on the can get plinkitis responses. Post hoc Scheffe tests $(\mathrm{p}<0.05)$ revealed that the Middle group of children was more likely to generalise to birds than the Young group. There were no other significant differences within categories as a function of age. There were no main or interaction effects associated with either health status or gender on all three exemplars.

\section{Configural Frequency Analysis}

In addition to the age and category differences identified in the ANOVAS, it was evident that different children presented different response patterns about the 
susceptibility to illness of entities belonging to different categories and according to exemplar. In order to explore these variations, Configural Frequency Analysis (CFA) was used. This form of non-parametric, multivariate analysis of association identifies response patterns which are over-represented (types) and under-represented (anti-types) given the null hypothesis that these patterns are normally and randomly distributed (Krauth, 1985; Von Eye,1990). Focusing on the children's choices of those entities which can get ill, the children's responses for each category were scored as follows: to those children who chose two or less entities in a category (i.e. a minority of entities) a score of 0 was given; to those children who chose three or more entities in a category (i.e. a majority of entities) a score of 1 was given. Therefore, each child had a score of 0 or 1 for each category and the resulting reponse pattern for each participant could be characterised as a sequence of $0 \mathrm{~s}$ and $1 \mathrm{~s}$, with the six categories being represented in the following order: humans, mammals, non-mammals, birds, plants and hand-made artifacts. The data thus generated were subjected to three CFAs, one for each of the three exemplars, child, dog and duck. The results are shown in Table 5, which reveals two response patterns for the child exemplar, four response patterns for the dog exemplar, and two responses patterns for the duck exemplar, all with frequencies significantly greater than would be expected by chance.

\section{* * INSERT TABLE 5 ABOUT HERE * *}

\section{Log Linear Analyses}

The results of the CFAs showed the children's judgement patterns on all three exemplars. In order to investigate the existence of any associations between the children's judgement patterns and either their age, health status or gender, a new variable was computed corresponding to whether or not each child presented each of the 
significant response judgement patterns. Three hierarchical log linear analyses were conducted for each exemplar respectively. The results revealed one significant association between gender and the children's response patterns for the child exemplar $\left(\chi^{2}(1)=3.84, p<0.05\right)$. Girls taught on the child exemplar were significantly more likely than boys to generalise to humans only (Pattern 100000: 34 girls and 20 boys). However, boys taught on the child exemplar were significantly more likely than girls to generalise to humans, mammals, non-mammals and birds (Pattern 111100: 18 boys and 11 girls). No other significant associations were found between the children's response patterns and their age, health status or gender.

\section{Discussion}

This study set out to examine children's conception of illness, using their naïve theory of biology as a framework theory. The children's assessments of susceptibility to illness displayed an awareness of the distinctiveness of the ontological categories. Depending on the exemplar used, the children's thinking revealed discontinuities between every category and its adjacent categories in almost all conditions (see Table 6). This supports the view that children do possess an early grasp of biological distinctions (Keil, 1989; Inagaki \& Hatano, 1996).

* * INSERT TABLE 6 ABOUT HERE * *

The only exceptions were the non-significant differences between the categories of plants and hand-made artifacts with the child and dog exemplars. The children generalised least of all to the entities in these two categories, though significantly more to the plants that the hand-made artifacts with respect to the duck exemplar. Contrary to 
the biological processes examined in other studies (Hatano et al., 1993; Backscheider et al., 1993; Inagaki \& Hatano, 1996), these findings suggest that plants may be less wellestablished as a distinct biological category with regard to illness generalisation, than the various animal (human, mammal, non-mammals and bird) categories amongst children of this age. However, it may be that there were particular considerations in this study which influenced the children's responses regarding the plant category.

First, the category of plants may present particular difficulties for children when asked to assess the likelihood of illness being transmitted to plants from other biological entities. If children do hold to a model of illness based on infection or contagion (Kalish, 1999), then the study required them to contemplate the methods for the transmission of infection between plants and other categories. The children may have concluded that the possibilities for transmission of plinkitis from humans or mammals to plants were less than across animal species. Secondly, the description of plinkitis, particularly with the reference to 'dizziness', 'staying still', and 'temperature' may have made the illness sound an unlikely one for plants. It might have been preferable to use more than one illness, and thus use a second imaginary illness with different symptoms, more applicable to plants, though the increased complexity might have been taxing for young children. Additionally, the actual reference to 'illness' itself may have caused problems, as in the English language plants are generally described as suffering from a disease rather than an illness. It might have been less confusing and closer to children's thinking to describe all the entities as 'getting sick'. Finally, it may take children longer to establish a concept of illness that can be generalised to plants+. Children generally have good opportunities to observe such biological processes in plants as the need for water and the ability to grow in size (Inagaki \& Hatano, 1996) or the ability to heal through re-growth after injury (Backscheider et al., 1993). However, not only is illness 
in plants a more uncommon phenomenon than taking in water or growing, but illness in any biological entity, other than human, may be an unusual experience for children. Therefore, children may require longer to attain a biological theory of illness and may need more time to extend it to plants, with these delays affecting their understanding of the status of plants in this particular study.

\section{Differences in Children's Thinking about Illness as a Function of Health Status}

One of the main aims of this study had been to examine differences in children's understanding of illness as a function of health status. Therefore this study examined the conceptual understanding of illness held by normally healthy and chronically-ill children. However, the ANOVAs revealed no main or interaction effects involving the children's health status. Furthermore, the log linear analyses, conducted on the patterns generated by the CFAs, also found no differences in the children's judgement patterns according to health status. These findings provide support for the view that the exposure to a chronic disease and/or medical treatment does not necessarily result in greater understanding of illness-related concepts (e.g. Perrin et al., 1991). They therefore run counter to the belief that health status does affect children's illness concepts (e.g. Rubovits \& Siegel, 1994).

However, there were some aspects of the study which may have affected any possible difference in the thinking of the two groups of children. First, difficulties in obtaining a sample of chronically-ill children resulted in a comparatively small number interviewed for the study (96 chronically-ill as opposed to 291 healthy children). Unfortunately, this was the maximum number of chronically-ill children that could be recruited for this study from the participating hospital. An additional problem resulting from the difficulties in obtaining chronically-ill children was the uneven distribution across the 
age groups, with the youngest children being over-represented and the oldest children under-represented in the sample (44 Young group, 31 Middle group and 20 Old group respectively. As some studies have suggested an interaction between age and experience, with older chronically-ill children displaying greater illness understanding (Campbell, 1975; Redpath \& Rogers, 1984; Crisp et al, 1996), this relatively small number of older chronically-ill children may have affected the outcome. However, the consistency with which health status failed to show any effects in any of the analyses, suggests that personal experience of chronic illness does not impact upon children's illness understanding, as measured by tasks tapping into their knowledge of ontological categories.

\section{Differences Associated with Age and Gender}

There were also surprisingly few differences associated with age or gender. With respect to the dog and duck exemplars, there were a few differences associated with age, suggesting some minor variations in the children's generalisation patterns at different ages. However, when children were taught on the child exemplar, there were no differences associated with age, with children in all three age groups making similar generalisations. This overall absence of age-based effects counters the claim of Carey (1985) that young children view humans as the prototypical entity. If this had been the case, the youngest group of children would have been expected to generalise more from the child exemplar than the older children. Furthermore, the overall paucity of differences associated with age suggest that children's illness concepts change relatively little over the age-range examined.

However, there were some significant differences between the oldest children and the adult participants, indicating that the oldest children's thinking had not yet attained fully 
adult-like understanding with respect to all categories and exemplars. With the child and dog exemplars, the patterns were the same: while there were no significant differences in generalisations to humans, plants or hand-made artifacts, adults were more likely to generalise to mammals, non-mammals and birds, indicating that children were still acquiring adult-like understanding of illness transference to these biological categories. On the other hand, with respect to the duck exemplar, there was only one significant difference between the oldest children and the adults: the children were significantly less likely than the adults to generalise the illness to humans, suggesting that children had yet to grasp the possibility of a disease contracted by birds being transferred to humans.

In addition to the lack of differences associated with age, no differences associated with gender were found in any of the ANOVAs conducted. There was one association with gender in the log linear analyses of the CFA-generated patterns. This suggested that the female participants were more likely than male to generalise plinkitis to humans only when taught on the child exemplar. The general lack of gender effects suggests that gender also may be discounted as a significant factor in children's thinking about illness concepts within the naïve theory of biology approach.

However, there are some alternative explanations for the lack of variations by age, gender or health status. First, it is possible that all of the children had a good understanding of the taxonomy presented so that no firm conclusions could be drawn concerning the development of conceptions of illness. This could be explored in future research by using a variety of properties in the task, including both illness and nonillness aspects; if non-illness aspects show exactly the same pattern as illness aspects, this would confirm children's early grasp of biological taxonomies. Secondly, the 
children may have been responding on projections of similarity of entity, rather than tapping their understanding of biological categories. This could be investigated by assessing similarity judgements and examining any links with illness generalisations.

\section{Differences Associated with Exemplars}

However, while there were few effects associated with either age and gender, the children did generalise differently according to which of the three exemplars they were taught on, when assessing the illness susceptibility of entities belonging to the six different categories. Children were significantly more likely to generalise to the same ontological category as the one to which the exemplar itself belonged. In other words, children tended to generalise more to the category of human beings when the child was the exemplar, to the category of mammals when the dog was the exemplar, and to the category of birds when taught on the duck exemplar.

Two different strategies have been proposed for children's generalisation of biological processes across ontological categories. Some researchers have suggested that young children tend to underattribute unobservable animal properties such as breathing to animals that are phylogenetically far from and physically dissimilar to humans (Carey, 1985; Inagaki \& Sugiyama, 1988). If this were the case, it would be expected that an imaginary illness such as plinkitis might elicit a similar pattern of generalisations from the children as an unobservable property. With the human exemplar, the children did tend to generalise first to humans, then to mammals, birds, non-mammals, and plants/hand-made artifacts in this order, thus following a pattern of generalisation which could have been based on how phylogenetically and physically different these entities were in comparison to humans. However, this was not the case with the other two exemplars; with both the dog and duck exemplars, the children were more likely to 
generalise plinkitis to entities in the same category as the exemplar, that is to other mammals and birds respectively. Furthermore, with respect to the CFAs, the children presenting significant patterns were more likely to generalise to other categories from the dog and duck exemplars (62\% and $77 \%$ respectively) than from the human exemplar to other categories (32\%). Therefore these results do not support the view that children's thinking is directed by a focus on human prototypicality.

The alternative strategy proposed for children's generalisations is category membership as opposed to surface or physical appearances (Flavell, 1985; Gelman \& Markman, 1986; Wellman \& Gelman, 1998). For example, Gelman and Markman (1986) found that children as young as two and a half based their attributions of an unknown property to biological entities on category membership rather than physical similarity despite conflicting physical appearances. The findings of this study support the view that children are capable of drawing their inferences from category membership, as for all three exemplars the children generalised significantly more to the ontological category to which the exemplar itself belonged. Thus the children's generalisations revealed a basic understanding of the distinctiveness of the different categories. This may be why Carey’s (1985) finding of human prototypicality was not supported.

\section{Conclusion}

In conclusion, the children did reveal a naïve theory of biology through a basic understanding of the various biological categories, as indicated by their generalisations of illness. Their judgements were unaffected by their health status, however, and largely unaffected by their age or gender. However, the children's generalisations did indicate that they were influenced by the type of exemplar on which they had been taught. Furthermore, while there was some evidence that the children did perceive plants as a 
separate category, they seemed less sure of the biological status of plants. However, this may have been due to specific aspects of the children's illness understanding, rather than an overall deficiency in their biological understanding.

\section{Acknowledgement}

This research was supported by Grant R000222514 from the Economic and Social Research Council of Great Britain 


\section{References}

Atran, S. 1998. Folk biology and the anthropology of science: cognitive universals and cultural particulars. Behavioral and Brain Sciences 21, 547-609

Backscheider A G, Shatz M, Gelman S A. 1993. Preschoolers' ability to distinguish living kinds as a function of regrowth. Child Development 64: 1242-1257

Berry S L, Hayford J R, Ross C K, Pachman L M, Lavigne J V. 1993. Conceptions of illness by children with Juvenile Rheumatoid Arthritis: A cognitive developmental approach. Journal of Paediatric Psychology 18: 83-97

Bibace R, Walsh M E. 1980. Development of children's conceptions of illness. Pediatrics 66: 912-917

Brewster A B. 1982. Chronically ill hospitalised children's concepts of their illness. Pediatrics 69: 355-362

Carey S. 1985. Conceptual Change in Childhood Cambridge MA: MIT Press

Carey S. 1995. On the origin of causal understanding. In S. Sperber, D. Premack, A J. Premack (Eds.), Causal Cognition (pp.268-302) Oxford: Clarendon Press

Campbell J. 1975. Illness is a point of view: the development of children's concepts of illness. Child Development 46: 92-100

Campbell E J, Scadding J G, Roberts R S. 1979. The concept of disease. British Medical Journal 29: 757-762

Crisp J, Ungerer J, Goodnow J. 1996.The impact of experience on children's understanding of illness. Journal of Pediatric Psychology 21: 57-72

Dunn L M, Dunn L M, Whetton C, Pintilie D. 1982. The British Picture Vocabulary Scale: Manual for the Short and Long Forms. The NFER-NELSON Publishing Company Ltd. 
Eiser, C. (1990). Children's knowledge of chronic disease and implication for education: A review. In L.R.Schmidt, P. Schwenkmezger, J.Weinman and S.Maes (Eds.). Theoretical and Applied Aspects of Health Psychology. Chur: Harwood Academic Publishers.

Eiser C, Town C, Tripp J H. 1988. Illness experience and related knowledge amongst children with asthma. Child: Care, Health, and Development 14: 11-24

Feldman W,Varni J W. 1985. Conceptualisations of health and illness by children with spina bifida. Children's Health Care 13: 102-108

Flavell J. 1985. Cognitive Development. Englewood Cliffs, NJ: Prentice-Hall.

Frazer J G. 1981. The Golden Bough. New York: Avenal.

Gelman S A, Markman E M. 1986. Categories and induction in young children. Cognition 23: 183-208

Hatano G, Inagaki K. 1994. Young children's naive theory of biology. Cognition 50: $171-188$.

Hatano G, Siegler R, Dean Richards D, Inagaki K, Stavy R, Wax N. 1993. The development of biological knowledge: a multi-national study. Cognitive Development 8: 47-62.

Hergenrather J R, Rabinowitz M. 1991. Age-related differences in the organisation of children's knowledge of illness. Developmental Psychology 27: 952-959

Inagaki K. 1997. Endogenous variables mediating disease transmission. Paper presented at the Biennial Meeting of the Society for Research in Child Development, Washington D.C., USA, April 1997.

Inagaki K, Hatano G. 1996. Young children's recognition of commonalities between animals and plants. Child Development 67: 2823-2840

Inagaki K, Sugiyama K. 1988. Attributing human characteristics: developmental 
changes in over-and underattribution. Cognitive Development 3: 55-80

Kalish C W. 1996. Preschoolers' understanding of germs as invisible mechanisms. Cognitive Development 11: 83-106

Kalish C W. 1999. What young children's understanding of contamination and contagion tells us about their concepts of illness. In M. Siegal, C. Peterson (Eds.), Children's Understanding of Biology and Health (pp.99-130) Cambridge: Cambridge University Press

Keil F C. 1989. Concepts, Kinds and Cognitive Development. Cambridge, MA: MIT Press

Kister M C, Patterson C J. 1980. Children's conceptions of the causes of illness: Understanding of contagion and use of immanent justice. Child Development 51: 839-849

Krauth J. 1985. Typological personality research by configural frequency analysis. Personality and Individual Difference 6: 161-168

Nagera H. 1978. Children's reactions to hospitalisation and illness. Child Psychology and Human Development 9: 3-19

Perrin E C, Sayer A G, Willett J. B. 1991. Sticks and stones may break my bones: Reasoning about illness causality and body functioning in healthy children and children who have a chronic illness. Pediatrics 88: 608-619

Redpath, C. \& Rogers, C. (1984). Healthy young children's concepts of hospitals, medical personnel, operations and illness. Journal of Pediatric Psychology 9: 29-39

Rosser R. 1994. Cognitive Development: Psychological and Biological Perspectives. Boston: Allyn and Bacon.

Rubovits D S, Siegel A W. 1994. Developing conceptions of chronic disease: a comparison of disease experience. Children's Health Care 23: 267-285 
Sayer A G, Willett J B, Perrin E C. 1993. Measuring understanding of illness causality in healthy children and in children with chronic illness: A construct validation. Journal of Applied Developmental Psychology 14: 11-36

Shagena M M, Sandler H K, Perrin E C. 1988. Concepts of illness and perception of control in healthy children and in children with chronic illnesses. Developmental and Behavioural Pediatrics 9: 252-256

Siegal M. 1988. Children's knowledge of contagion and contamination as causes of illness. Child Development 59: 1353-1359

Siegelman C, Maddock A, Epstein J, Carpenter W. 1993. Age differences in understandings of disease causality: AIDS, colds and cancer. Child Development 64: $272-284$

Solomon G, Cassimatis N. 1999. On facts and conceptual systems: young children's integration of their understandings of germs and contagion. Developmental Psychology 35: 113-126

VonEye A. 1990. Introduction to Configural Frequency Analysis. Cambridge: Cambridge University Press

Wellman H M, Gelman S A. 1992. Cognitive development: Foundational theories or core domains. Annual Review of Psychology 43: 337-375.

Wellman H M, Gelman S A. 1998. Knowledge acquisition in foundational domains. In D. Kuhn, R S. Siegler (Eds.), Handbook of Child Psychology vol 2 (pp.523-574) John Wiley \& Sons: New York 
Table 1: Child Exemplar: children's and adults' mean responses to who can get plinkitis (standard deviations in parentheses)

\begin{tabular}{|c|c|c|c|c|c|}
\hline & \multicolumn{5}{|c|}{ Can get plinkitis } \\
\hline & \multicolumn{4}{|c|}{ children } & \multirow[t]{2}{*}{ adults } \\
\hline Category & young & middle & old & total & \\
\hline Humans & $3.93(1.4)$ & $4.60(1.0)$ & $4.58(1.0)$ & $4.32(1.2)$ & $4.80(0.6)$ \\
\hline Mammals & $2.42(1.8)$ & $2.30(1.9)$ & $2.41(2.0)$ & $2.38(1.9)$ & $3.53(2.2)$ \\
\hline Non-mammals & $2.01(1.7)$ & $1.50(1.7)$ & $1.41(1.8)$ & $1.68(1.7)$ & $2.60(2.17)$ \\
\hline Birds & $2.00(1.7)$ & $1.97(2.0)$ & $2.13(2.0)$ & $2.03(1.9)$ & $3.13(2.17)$ \\
\hline Plants & $0.62(1.1)$ & $0.17(0.5)$ & $0.08(0.5)$ & $0.33(0.8)$ & $0.33(1.03)$ \\
\hline Artifacts & $0.32(0.7)$ & $0.02(0.1)$ & $0.10(0.4)$ & $0.17(0.5)$ & $0.10(0.31)$ \\
\hline mean scores & 1.88 & 1.76 & 1.78 & 1.81 & \\
\hline ANOVA & \multicolumn{4}{|c|}{ category: $\mathrm{F}(5,129)=96.26, \mathrm{p}<0.001$} & $\begin{array}{l}\text { Category: } F(1,29) \\
=328.67, \mathrm{p}<0.001\end{array}$ \\
\hline
\end{tabular}


Table 2: Dog Exemplar: children's and adults' mean responses to who can get plinkitis (standard deviations in parentheses)

\begin{tabular}{|c|c|c|c|c|c|}
\hline & \multicolumn{5}{|c|}{ Can get plinkitis } \\
\hline & \multicolumn{4}{|c|}{ children } & \multirow[t]{2}{*}{ adults } \\
\hline Category & young & middle & old & total & \\
\hline Humans & $1.58(1.9)$ & $2.18(2.3)$ & $2.79(2.3)$ & $2.15(2.2)$ & $3.91(2.1)$ \\
\hline Mammals & $3.54(1.3)$ & $4.04(1.3)$ & $4.02(1.1)$ & $3.85(1.2)$ & $4.52(1.2)$ \\
\hline Non-mammals & $2.60(1.5)$ & $2.50(1.7)$ & $1.88(1.6)$ & $2.34(1.6)$ & $2.67(1.9)$ \\
\hline Birds & $2.88(1.6)$ & $3.63(1.7)$ & $2.56(1.9)$ & $3.02(1.8)$ & $3.61(2.0)$ \\
\hline Plants & $0.36(0.6)$ & $0.18(0.6)$ & $0.15(0.8)$ & $0.23(0.6)$ & $0.15(0.7)$ \\
\hline Artifacts & $0.22(0.5)$ & $0.04(0.2)$ & $0.04(0.2)$ & $0.10(0.3)$ & 0 \\
\hline mean scores & 1.86 & 2.09 & 1.90 & 1.94 & 2.49 \\
\hline ANOVA & \multicolumn{4}{|c|}{$\begin{array}{l}\text { Category: } \mathrm{F}(5,122)=119.76, \mathrm{p}<0.001 \\
\text { Age } x \text { category: } \mathrm{F}(10,242)=2.64, \mathrm{p}<0.01\end{array}$} & $\begin{array}{l}\text { Category: } \mathrm{F}(1,32) \\
=95.82, \mathrm{p}<0.001\end{array}$ \\
\hline
\end{tabular}

Children:

Scheffe tests: significant differences between age groups

Humans: Young group vs Old group

Birds: Middle group vs Old group 
Table 3: Duck Exemplar: children's and adults' mean responses to who can get plinkitis (standard deviations in parentheses)

\begin{tabular}{|c|c|c|c|c|c|}
\hline & \multicolumn{5}{|c|}{ Can get plinkitis } \\
\hline & \multicolumn{4}{|c|}{ children } & \multirow[t]{2}{*}{ adults } \\
\hline Category & young & middle & old & total & \\
\hline Humans & $2.33(2.0)$ & $1.81(2.2)$ & $2.65(2.3)$ & $2.29(2.2)$ & $3.85(2.1)$ \\
\hline Mammals & $3.24(1.5)$ & $3.05(1.7)$ & $3.00(1.8)$ & $3.11(1.7)$ & $3.85(1.8)$ \\
\hline Non-mammals & $2.85(1.4)$ & $2.54(1.7)$ & $2.25(1.4)$ & $2.57(1.5)$ & $2.94(1.9)$ \\
\hline Birds & $3.40(1.3)$ & $4.27(1.0)$ & $4.02(1.1)$ & $3.84(1.2)$ & $4.52(1.1)$ \\
\hline Plants & $0.64(1.2)$ & $0.37(0.8)$ & $0.25(0.8)$ & $0.44(1.0)$ & $0.12(0.4)$ \\
\hline Artifacts & $0.31(0.7)$ & $0.05(0.2)$ & $0.06(0.3)$ & $0.16(0.5)$ & $0.03(0.2)$ \\
\hline mean scores & 2.12 & 2.01 & 2.03 & 2.06 & 2.55 \\
\hline ANOVA & \multicolumn{4}{|c|}{ Category: $\mathrm{F}(5,118)=131.09, \mathrm{p}<0.001$} & $\begin{array}{l}\text { Category: F }(1,32) \\
107.74, p<0.001\end{array}$ \\
\hline
\end{tabular}

Children:

Scheffe tests: significant differences between age groups

Birds: Young group vs Middle group 
Table 4: Post hoc t-tests (Bonferroni corrected) to locate differences between ontological categories and exemplar

\begin{tabular}{|c|c|c|c|}
\hline & $\begin{array}{c}\text { Child } \\
\text { (t values) } \\
\text { df }=144\end{array}$ & $\begin{array}{c}\text { Dog } \\
\text { (t values) } \\
\text { df }=137\end{array}$ & $\begin{array}{c}\text { Duck } \\
\text { (t values) } \\
\text { df }=133\end{array}$ \\
\hline Humans v mammals & $10.12 * *$ & $-8.40 * *$ & $-4.21 * *$ \\
\hline Humans v non-mammals & $14.37 * *$ & ns & Ns \\
\hline Humans v plants & $25.93 * *$ & $7.48 * *$ & $8.97 * *$ \\
\hline Humans v birds & $12.18 * *$ & $-3.60 * *$ & $-8.01 * *$ \\
\hline Humans $\mathrm{v}$ artifacts & $31.07 * *$ & $10.26 * *$ & $11.23 * *$ \\
\hline Mammals v non-mammals & $5.98 * *$ & $11.22 * *$ & $4.37 * *$ \\
\hline Mammals v plants & $12.46^{* *}$ & $28.77 * *$ & $15.59 * *$ \\
\hline Mammals v birds & $3.31 * *$ & $6.20 * *$ & $-5.12 * *$ \\
\hline Mammals v artifacts & $13.51 * *$ & $31.34 * *$ & $19.14 * *$ \\
\hline Non-mammals v plants & $9.49 * *$ & $14.08 * *$ & $13.94 * *$ \\
\hline Non-mammals v birds & $-3.13 * *$ & $-4.95 * *$ & $-8.73 * *$ \\
\hline Non-mammals v artifacts & $10.30 * *$ & $15.33 * *$ & $17.86 * *$ \\
\hline Plants v birds & $10.32 * *$ & $17.36 * *$ & $23.25 * *$ \\
\hline Plants v artifacts & ns & ns & $3.41 * *$ \\
\hline Birds $v$ artifacts & $11.41 * *$ & $18.15^{* *}$ & $30.04 * *$ \\
\hline
\end{tabular}

$\mathrm{p}<0.003 * * \quad \mathrm{~ns}=$ non-significant 
Table 5: Configural Frequency Analysis response patterns by exemplar (Bonferroni corrected)

\begin{tabular}{|l|c|c|c|}
\hline Exemplar & Pattern* & Frequency & Z score \\
\hline Child & 100000 & 54 & 6.5 \\
\cline { 2 - 4 } & 111100 & 29 & 7.4 \\
\hline \multirow{3}{*}{ Dog } & 011100 & 28 & 6.5 \\
\cline { 2 - 4 } & 111100 & 20 & 5.2 \\
\cline { 2 - 4 } & 010000 & 18 & 4.3 \\
\cline { 2 - 4 } & 000000 & 12 & 3.7 \\
\hline Duck & 111100 & 30 & 5.4 \\
\cline { 2 - 4 } & 000000 & 9 & 3.5 \\
\hline
\end{tabular}

*order of categories in pattern: humans, mammals, non-mammals, birds, plants and artifacts

$\mathrm{p}<0.0007$ 
Table 6: Pattern of discontinuities between categories for all three exemplars

\begin{tabular}{|l|l|l|l|l|l|l|l|l|l|l|l|}
\hline & humans & & mammals & & non- & & birds & & plants & & artifacts \\
\hline child & & $*$ & & $*$ & & $*$ & & $*$ & & & \\
\hline $\operatorname{dog}$ & & $*$ & & $*$ & & $*$ & & $*$ & & & \\
\hline duck & & $*$ & & $*$ & & $*$ & & $*$ & & $*$ & \\
\hline
\end{tabular}

* asterisks denote the location of the significant differences between adjacent ontological categories 